PROFESSOR AT LARGE 
In loving memory of Gerri Jones 


\section{PROFESSOR AT LARGE}

\section{The Cornell Years}

\section{JOHN CLEESE}

CORNELL UNIVERSITY PRESS

Ithaca and London 
Copyright @ 2018 by Cornell University

All rights reserved. Except for brief quotations in a review, this book, or parts thereof, must not be reproduced in any form without permission in writing from the publisher. For information, address Cornell University Press, Sage House, 512 East State Street, Ithaca, New York 14850. Visit our website at cornellpress.cornell.edu.

First published 2018 by Cornell University Press

Printed in the United States of America

Library of Congress Cataloging-in-Publication Data

Names: Cleese, John, author. | Ceci, Stephen J., writer of introduction.

Title: Professor at large : the Cornell years / John Cleese.

Description: Ithaca : Cornell University Press, 2018.

Identifiers: LCCN 2018012833 (print) | LCCN 2018019175 (ebook)

| ISBN 9781501716591 (e-book epub/mobi) | ISBN

9781501716607 (e-book pdf) | ISBN 9781501716577 | ISBN

9781501716577 (cloth ; alk. paper)

Subjects: LCSH: Cleese, John. | Cornell University-Faculty. |

Comedians-Great Britain-Interviews. | Motion picture actors and actresses-Great Britain-Interviews.

Classification: LCC PN2598.C47 (ebook) | LCC PN2598.C47 A5 2018 (print) | DDC 792.702/8092 [B] - dc23

LC record available at https://lccn.loc.gov/2018012833

Cover photo by Paul Marotta/Getty Images 